\title{
Drifting along in the open-ocean: The associative behaviour of oceanic triggerfish and rainbow runner with floating objects
}

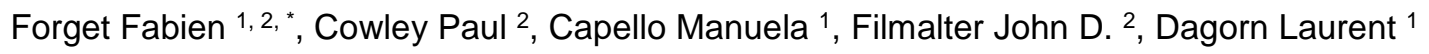 \\ 1 MARBEC, University of Montpellier, CNRS, IFREMER, IRD, Sete, France \\ ${ }^{2}$ South African Institute for Aquatic Biodiversity (SAIAB), Grahamstown, South Africa \\ * Corresponding author : Fabien Forget, email address : fabienforget@gmail.com
}

\begin{abstract}
:
Multispecies aggregations at floating objects are a common feature throughout the world's tropical and subtropical oceans. The evolutionary benefits driving this associative behaviour of pelagic fish remains unclear and information on the associative behaviour of non-tuna species remains scarce. This study investigated the associative behaviour of oceanic triggerfish (Canthidermis maculata) and rainbow runner (Elagatis bipinnulata), two major bycatch species in the tropical tuna purse seine fishery, at floating objects in the western Indian Ocean. A total of 24 rainbow runner and 46 oceanic triggerfish were tagged with acoustic transmitters at nine drifting FADs equipped with satellite linked receivers. Both species remained associated with the same floating object for extended periods; Kaplan-Meier survival estimates (considering the censored residence time due to equipment failure and fishing) suggested that mean residence time by rainbow runner and oceanic triggerfish was of 94 and 65 days, respectively. During daytime, the two species increased their home range as they typically performed short excursions $(<2 \mathrm{~h})$ away from the floating objects. Rainbow runner performed more excursions per unit time than oceanic triggerfish; the mean excursion index was 0.86 ( $\pm 0.8 \mathrm{SD}$ ) for oceanic triggerfish and $1.31( \pm 1.1 \mathrm{SD})$ for rainbow runner. Ambient light intensity appears to be the stimulus triggering the onset and end of the associative modes. The observed prolonged residency of these two major bycatch species suggests that they are more vulnerable to the tropical tuna purse seine gear than the targeted tuna species.
\end{abstract}

\section{Highlights}

- The associative behaviour of oceanic triggerfish (Canthidermis maculata) and rainbow runner (Elagatis bipinnulata) were investigated using acoustic telemetry satellite linked receivers at floating objects in the western Indian Ocean. - Both species remained associated with the same floating object for extended periods with mean residency estimated at 94 days for rainbow runner and 65 days for oceanic triggerfish. A strong diel pattern was observed for both species with short excursions $(<2 \mathrm{~h})$ away from the floating objects observed during the day. Ambient light intensity appears to be the stimulus triggering the onset and end of the associative modes. - The observed prolonged residency of these two major bycatch species suggests that they are more vulnerable to the tropical tuna purse seine gear than the targeted tuna species. 


\section{Introduction}

Large multispecies aggregations at floating objects are a common feature of the world's tropical and subtropical oceans. While a total of 333 species have been recorded at floating objects [Castro2001], it appears that far fewer, approximately 20 species, regularly associate with floating objects [Kingsford1993, Taquet2007]. Numerous hypotheses have been proposed to explain the causes of this associative behaviour [Castro2001, Freon2000]. An initial hypothesis was that fish use floating objects as shelter to reduce predation [Gooding1967, Hunter1967, Rountree1989]. While underwater observations provide some support to this hypothesis for small fish [Gooding1967], it does not appear to be valid for larger schooling species such as tunas. Other authors have suggested that association could be driven by trophic advantages, by predating on associated fish [Gooding1967, Kojima1956]. While predation events have been observed at fish aggregating devices (FADs) ([Hunter1967], unpublished personal observation), diet studies of tropical tunas and dorado (Coryphaena hippurus) tend to indicate that the associated fauna does not represent a major component of the diet of predators at floating objects [Taquet2004, Menard2000]. The meeting point hypothesis suggests that fish use the floating object as a spatial reference point to facilitate schooling behaviour and form larger schools [Dagorn1999, Freon2000]. Another motive that has been suggested is that floating objects act as good indicators of productive environments by accumulating in rich frontal areas [Bakun2006, $\underline{\text { Hall1992]. }}$

A striking characteristic of multispecies aggregations is that the community appears to be spatially structured relative to the floating objects. [Kojima1960] was the first to propose a categorisation of the community based on radial distribution relative to the floating objects. [Parin1992] then proposed three broad categories of spatial distribution: intranatant $(<50 \mathrm{~cm}$ from the object), extranatant $(50 \mathrm{~cm}$ to $2 \mathrm{~m}$ from the object) and circumnatant $(>2 \mathrm{~m}$ from the object) and subsequently, [Freon2000] proposed some distance modifications for these categories. However, none of these categories were determined empirically [Girard2007]. Acoustic telemetry studies have allowed for empirical investigations on the distribution range of FAD-associated species, which varied from 300-400 $\mathrm{m}$ for dorado [Taquet2007a] to 5-10 $\mathrm{km}$ for tunas [Dagorn2000c, Holland1990, Matsumoto2014]. With similar intent, [Moreno2007a] used acoustic surveys to observe the spatial distribution of biomass at floating objects and while distinct structures could be identified, species specific details could not be determined. Other than tunas, oceanic triggerfish (Canthidermis maculata) and rainbow runner (Elagatis bipinnulata) often form the bulk of the aggregations around floating objects [Romanov2002b, Lezama-Ochoa2015a, Amande2011], yet little is known about their associative behaviour, ecology or potential role in multispecies aggregation dynamics. Large schools of skipjack (Katsuwonus pelamis), yellowfin (Thunnus albacares) and bigeye tuna (T. obesus) are found at floating objects and fisherman have used floating objects as a visual cue to locate pelagic fish in the open ocean. In the early 80 's, tropical purse seiners started to deploy man-made floating objects (i.e. FADs), which were subsequently equipped with electronic buoys to facilitate their relocation [Fonteneau2000]. This strategy proved to be highly effective and rapidly lead to a massive increase in FAD deployments [Fonteneau2000]. Moreover, since the mid 2000s, FADs were equipped with echosounder buoys that provided fishermen with biomass estimates of target tuna species, allowing them to locate larger schools and considerably increased their fishing efficiency [Fonteneau2013, Lopez2014]. The annual landing of the tropical tuna purse seine fishery accounts for 5 million tons of tuna of which about $60 \%$ originates from fishing on floating objects [Dagorn2013, ISSF 2019]. In the Indian Ocean, the total catch of tropical tuna is about 1 million tons with the purse seine fishery. The recent implementation of a yellowfin tuna quota in the Indian Ocean considerably increased the effort on FAD fishing as the proportion 
of FAD sets by purse seine fleets now represents between $90-96 \%$ (fleet dependent) of total sets [Fiorellato et al. 2019]. The multispecies nature of aggregations around floating objects means that this practice generates 2.8-6.7 times (ocean dependant) more bycatch than when fishing on free-swimming tuna schools [Dagorn2013]. The most dominant incidentally captured non-target species at FADs include dorado, rainbow runner, oceanic triggerfish, wahoo (Acanthocybium solandri) and silky shark (Carcharhinus falciformis)[Amande2011a, Amande2011, Romanov2002b]. Owing to higher bycatch rates and the preponderance of the FAD-based fishery, concerns have been raised on its impacts on pelagic ecosystems and the sustainability of this fishing practice has been questioned [Hall1996, Hall2000, Gilman2011]. Moreover, some authors suggested that drifting FADs could act as an ecological trap for associated species. The ecological trap hypothesis suggests that massive seeding of drifting FADs could have negative impact on the populations of associated species by altering the natural movements of populations towards less favourable environments which could lead to an increase in natural mortality and population declines [Marsac2000, $\underline{\text { Hallier2008a] }}$. Currently, little to no data is available on the basic biology, ecology and behaviour of oceanic triggerfish and rainbow runner associated with FADs. Information on their behaviour may contribute towards a better understanding of the causes driving associative behaviour and provide essential elements to a holistic understanding of multispecies aggregations at floating objects. Additionally, with an increased emphasis placed on ecosystem based management, key ecological parameters of captured species are required to evaluate the impacts of fishing mortality on the ecosystem. This study aimed to characterise the associative behaviour of oceanic triggerfish and rainbow runner at floating objects using acoustic telemetry. The objectives were to 1 ) estimate the residency at floating objects 2) examine temporal patterns in association, 3 ) determine if there is a species specific associative pattern and evaluate the degree of similarity between individuals of the two species.

\section{Materials and methods}

\section{Acoustic tagging}

Four scientific cruises were conducted in the western Indian Ocean between March 2010 and April 2012. These cruises took place in the Mozambique Channel and around the Seychelles Archipelago. Drifting FADs were located through collaboration with European purse seine skippers. Firstly, a VR4-Global (VEMCO, Amarix Ltd., Canada) acoustic receiver was attached to the drifting FAD. These receivers utilise the Iridium satellite system to transmit acoustic detection logs from tagged individuals on a daily basis. Oceanic triggerfish and rainbow runner were caught using rod and reels or hand lines. Coded acoustic transmitters (V9, V9P, V9TP and V9AP (120 s nominal delay, $69 \mathrm{kHz}, 1 \mathrm{H}$; Table 1) were surgically implanted into the peritoneal cavity following the standard methods implantation technique [Dagorn2007a, Schaefer2004]. Captured individuals were brought onboard using a scoop net and placed on $\mathrm{V}$-shaped tagging table. The fish were then rapidly examined to verify that no injuries were sustained during capture. Only individuals that appeared to be in good condition were tagged. The head of the fish was covered with a wet cloth, a hose pumping seawater was placed by the mouth to irrigate the gills and a small incision $(\sim 2 \mathrm{~cm})$ was made close to the ventral midline into the peritoneal cavity. The tag was implanted into the peritoneal cavity and two independent sutures were made to close the incision, the length of the fish was then measured to the closest $0.5 \mathrm{~cm}$ (fork length for rainbow runner and total length for oceanic triggerfish) and the fish was then released in close proximity $(<100 \mathrm{~m})$ to the monitored FAD. Once tagging was complete, the FAD and attached VR4-Global receiver were left to drift and the data was relayed remotely. Daily detection logs and position logs from the VR4Global receiver were then consolidated into a database for subsequent analysis. The FAD 

1).

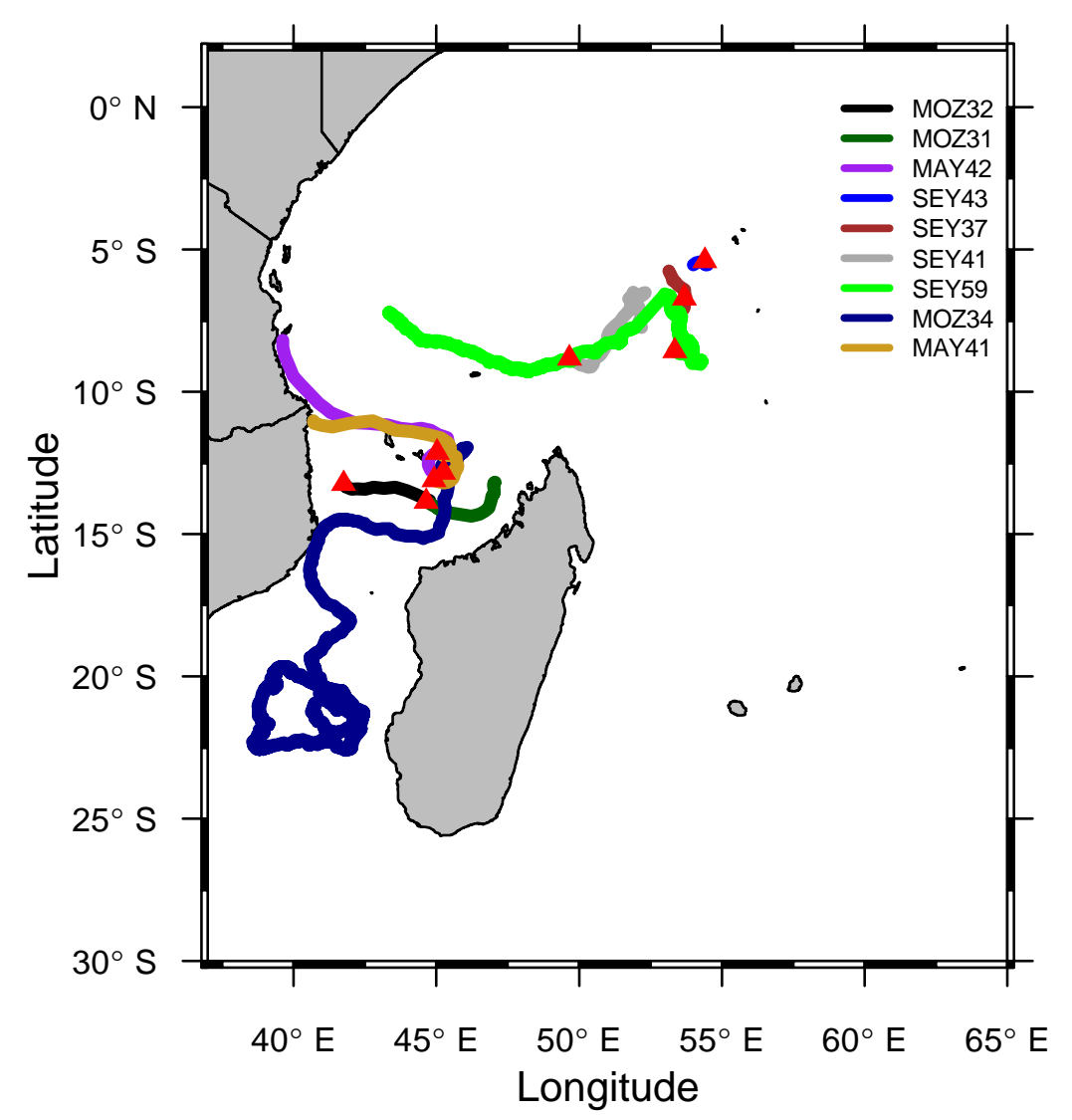

Figure 1: Drift trajectories of the nine experimental FADs monitored in the western Indian Ocean. Red triangles indicate the starting point of the experiments.

\section{Data Analysis}

\section{Residency}

The total residence time (TRT) provides an indication of the residency of tagged fish at FADs. TRT is defined as the amount of time between the first detection and last detection before the fish permanently left the FAD. The time when an individual first associated with the floating object, prior to the experiment, is unknown. Hence, the real residency of individuals remains unknown. Additionally, some experiments were prematurely interrupted by either commercial fishing operations, resulting in the capture of the entire FAD aggregation, or by equipment failure. TRTs that were not interrupted artificially indicate that the individuals left the FAD of their own accord and were recorded as "natural departures". In order to standardise the varying experimental durations to allow comparisons between the different FADs where tagging was conducted, a residency index was calculated for each individual. This index was calculated by dividing the TRT by the experimental duration for each FAD (Table 1 ). This standardised index ranges from 0 to 1 and is commonly used in acoustic telemetry to provide estimates of the relative residency of tagged individuals within an acoustic telemetry array [Afonso2012, Ledee2015]. In order to estimate the durations of residency of the two species at FADs, a survival analysis of the TRT was conducted. Survival analysis was used to analyse data where the outcome variable is the time until the occurrence of a particular event (here departure from FAD) with the added ability to handle censored 
observations (i.e. truncations). Survival analysis has previously been used in acoustic telemetry experiments with truncated data [Ohta2005, Robert2012a, Stehfest2013]. KaplanMeier estimates of the survivor function of TRTs was calculated with $95 \%$ confidence intervals. For comparative purposes, two Kaplan-Meier survival functions were generated using i) TRTs considering censored data (i.e. stratified into natural departures and censored data) and, ii) all TRTs with no censoring considered (i.e. all TRTs) to provide residence time estimations and assess the effect of censored data on estimates. A log-rank test was used to test the differences in survival functions between the two species. An exponential survival regression model was then fitted to each of the censored and uncensored curves to provide an estimation of residency for the two species at FADs. A constant hazard assumption was made for the regression model, whereby the probability of leaving the FAD was independent of time. Additionally, the mean of the uncensored TRT was calculated to allow comparisons with other studies reporting residency at FADs.

\section{Temporal patterns in association}

173 Detection timelines were constructed for each FAD depicting all detections of tagged individuals and were visually inspected to assess the patterns in the detection rates. Additionally, detection time series were converted into hourly detection time series and hourly chronograms were constructed to examine temporal patterns in associative behaviour.

Cyclical patterns in the associative behaviour of each individual were examined through a fast fourier transformation (FFT) applied to the hourly detection rates and the resulting spectral density was plotted. FFT indicates whether rhythmic patterns existed in the presence of tagged individuals at FADs [Barnett2012]. Distinct peaks in the spectral density indicates the presence of cyclic rhythms and the time scale at which they occur, denoting the periodicity. The spectral analysis was performed on individuals that had $\geq 5$ days of data to ensure sufficient sample size for the analysis. Additionally, a continuous wavelet transformation (CWT) was computed to examine the stability of the cyclic rhythms, such as a diel pattern, over time. The CWT decomposes a time series into time-frequency space [Percival2000] and has previously been used to examine cyclic rhythms in fish behaviour [Alos2012a, March2010]. Morlet wavelets, using the "dplR" package in R, was used to construct a 2 -dimensional wavelet spectrum and calculate a point wise test with a $95 \%$ significance level. Spectrograms were then inspected to determine how persistent the cyclic rhythms were over time according to the significance of the signal.

Gaps in the detection time series are indicative of periods when individuals ventured outside the range of the receiver. Excursions were defined as a detection gap of $>1$ hour and were used as temporal units to describe movements away from the FAD [Capello2015]. To assess the level of variability in the excursion behaviour amongst individuals an excursion index (EI) was calculated by dividing the total number of excursions by the TRT. This time standardised index reflects the excursion activity of individuals and provided the number of excursions per day. A high index value indicates more frequent excursions per unit time. The distribution and durations of excursions were then examined over $24 \mathrm{hrs}$.

A cluster analysis was conducted to determine the degree of similarity, and synchronicity, amongst individuals and whether there was a species-specific pattern in associations. First, the detection time series were converted into hourly presence-absence time series to remove the potential effect of detection variance and acoustic collisions. Secondly, for each FAD, the hourly presence-absence time series were trimmed synchronously to obtain the 
same time segments for each individual. Finally, a hierarchical clustering was computed using the Ward algorithm on euclidean distance matrices based on the presence-absence time series at each FAD using the R software [RCoreTeam2014].

\section{Results}

215 A total of 24 rainbow runner and 46 oceanic triggerfish were tagged at nine drifting FADs

216 (Fig.1). Details of the tagging information are provided in Table 1 . All 70 individuals were

217 detected at the FAD where they were released. The cumulative number of observation days at

218 FADs was $919.5 \mathrm{~d}$ for oceanic triggerfish and $538.1 \mathrm{~d}$ for rainbow runner, yielding a total of

219273866 and 114397 detections, respectively.

Table 1: Metadata of oceanic triggerfish (TRI) and rainbow runner (ELA) tagged at drifting FADs. TRT is the total residence time. * Denotes TRT with natural departures from FAD.

\begin{tabular}{|c|c|c|c|c|c|c|c|c|c|c|}
\hline \multicolumn{2}{|c|}{ Tagging } & Species & Size & FAD ID & \multicolumn{2}{|c|}{ Acoustic tag } & \multirow{2}{*}{$\begin{array}{l}\text { Experiment } \\
\text { Duration (days) }\end{array}$} & \multirow[b]{2}{*}{ TRT } & \multicolumn{2}{|c|}{ Excursion } \\
\hline Date & Time & & $(\mathrm{TL} / \mathrm{FL} \mathrm{cm})$ & & Type & ID & & & Num. & Index \\
\hline $15 / 04 / 11$ & $11: 56$ & TRI & 31.0 & MAY41 & V9TP & 3601 & 21.4 & 20.7 & 1 & 0.0 \\
\hline $15 / 04 / 11$ & $11: 42$ & TRI & 30.0 & MAY41 & V9TP & 3603 & 21.4 & 21.3 & 1 & 0.0 \\
\hline $15 / 04 / 11$ & $16: 27$ & TRI & 32.0 & MAY41 & V9P & 64826 & 21.4 & 20.7 & 11 & 0.5 \\
\hline $15 / 04 / 11$ & $16: 04$ & TRI & 30.0 & MAY41 & V9P & 64827 & 21.4 & 20.7 & 58 & 2.8 \\
\hline $15 / 04 / 11$ & 22:01 & TRI & 33.0 & MAY41 & V9P & 64828 & 21.4 & 20.5 & 14 & 0.7 \\
\hline $16 / 04 / 11$ & $07: 15$ & TRI & 33.0 & MAY41 & V9P & 64829 & 21.4 & 20.7 & 16 & 0.8 \\
\hline $16 / 04 / 11$ & $23: 48$ & TRI & 34.0 & MAY41 & V9P & 64830 & 21.4 & 21.1 & 9 & 0.4 \\
\hline $16 / 04 / 11$ & $21: 46$ & TRI & 30.0 & MAY41 & V9P & 64831 & 21.4 & 21.12 & 20 & 0.9 \\
\hline $16 / 04 / 11$ & $22: 25$ & TRI & 36.0 & MAY41 & V9P & 64832 & 21.4 & 21.12 & 38 & 1.8 \\
\hline $16 / 04 / 11$ & - & TRI & 30.0 & MAY41 & V9P & 64834 & 21.4 & $1.6^{*}$ & 0 & 0.0 \\
\hline $20 / 04 / 11$ & $11: 59$ & ELA & 24.0 & MAY42 & V9TP & 3599 & 26.9 & $16.8^{*}$ & 1 & 0.1 \\
\hline $20 / 04 / 11$ & $12: 16$ & ELA & 23.0 & MAY42 & V9P & 30112 & 26.9 & 24.3 & 70 & 2.9 \\
\hline $20 / 04 / 11$ & $18: 45$ & ELA & 23.0 & MAY42 & V9P & 30114 & 26.9 & 24.6 & 81 & 3.3 \\
\hline $20 / 04 / 11$ & 08:02 & ELA & 23.5 & MAY42 & V9P & 64819 & 26.9 & 24.7 & 56 & 2.3 \\
\hline $21 / 04 / 11$ & - & ELA & 23.5 & MAY42 & V9P & 64835 & 26.9 & 24.7 & 66 & 2.7 \\
\hline $20 / 04 / 11$ & $11: 46$ & TRI & 32.5 & MAY42 & V9P & 3605 & 26.9 & 24.3 & 16 & 0.7 \\
\hline $20 / 04 / 11$ & 11:05 & TRI & 32.5 & MAY42 & V9P & 30113 & 26.9 & $10.5^{*}$ & 4 & 0.4 \\
\hline $20 / 04 / 11$ & $07: 43$ & TRI & 36.5 & MAY42 & V9P & 64820 & 26.9 & $10.1 *$ & 2 & 0.2 \\
\hline $20 / 04 / 11$ & $07: 10$ & TRI & 34.0 & MAY42 & V9P & 64821 & 26.9 & $8.0^{*}$ & 13 & 1.6 \\
\hline $20 / 04 / 11$ & 07:01 & TRI & 31.0 & MAY42 & V9P & 64822 & 26.9 & $8.0^{*}$ & 6 & 0.7 \\
\hline $21 / 04 / 11$ & $16: 50$ & TRI & 32.0 & MAY42 & V9P & 64823 & 26.9 & $9.1 *$ & 8 & 0.9 \\
\hline $21 / 04 / 11$ & $16: 35$ & TRI & 35.0 & MAY42 & V9P & 64824 & 26.9 & $9.0 *$ & 9 & 1.0 \\
\hline $15 / 03 / 10$ & $18: 21$ & TRI & 33.0 & MOZ31 & V9P & 64810 & 11.6 & 11.5 & 2 & 0.2 \\
\hline $15 / 03 / 10$ & $18: 13$ & TRI & 33.0 & MOZ31 & V9P & 64811 & 11.6 & $7.3^{*}$ & 1 & 0.1 \\
\hline $16 / 03 / 10$ & 18:06 & TRI & 31.0 & MOZ31 & V9P & 64813 & 11.6 & 10.8 & 28 & 2.6 \\
\hline $16 / 03 / 10$ & $17: 58$ & TRI & 32.0 & MOZ31 & V9P & 64814 & 11.6 & 10.8 & 3 & 0.3 \\
\hline $16 / 03 / 10$ & $17: 45$ & TRI & 33.0 & MOZ31 & V9P & 64815 & 11.6 & 9.3 & 2 & 0.2 \\
\hline $16 / 03 / 10$ & $07: 37$ & TRI & 33.0 & MOZ31 & V9P & 64816 & 11.6 & 10.8 & 0 & 0.0 \\
\hline $16 / 03 / 10$ & $16: 17$ & TRI & 33.0 & MOZ31 & V9P & 64817 & 11.6 & 10.8 & 1 & 0.1 \\
\hline
\end{tabular}




\begin{tabular}{|c|c|c|c|c|c|c|c|c|c|c|}
\hline \multicolumn{11}{|c|}{ Journal Pre-proof } \\
\hline $21 / 04 / 11$ & 07:04 & TRI & 32.0 & MOZ32 & V9P & 64809 & 10.8 & 11.0 & 0 & 0.0 \\
\hline 08/03/10 & $11: 25$ & ELA & 45.0 & MOZ34 & V9P & 64804 & 67.0 & 67.0 & 172 & 2.6 \\
\hline 08/03/10 & $11: 39$ & ELA & 43.0 & MOZ34 & V9P & 64805 & 67.0 & 67.0 & 172 & 2.6 \\
\hline $09 / 03 / 10$ & $18: 53$ & TRI & 28.0 & MOZ34 & V9 & 54304 & 67.0 & $26.8 *$ & 18 & 0.7 \\
\hline $09 / 03 / 10$ & $11: 13$ & TRI & 31.0 & MOZ34 & V9 & 54305 & 67.0 & 66.2 & 171 & 2.6 \\
\hline $09 / 03 / 10$ & $11: 59$ & TRI & 39.0 & MOZ34 & V9P & 64806 & 67.0 & 66.2 & 80 & 1.2 \\
\hline $09 / 03 / 10$ & $12: 05$ & TRI & 34.0 & MOZ34 & V9P & 64807 & 67.0 & $12.5^{*}$ & 9 & 0.7 \\
\hline $09 / 03 / 10$ & $07: 19$ & TRI & 30.0 & MOZ34 & V9P & 64808 & 67.0 & $26.4^{*}$ & 34 & 1.3 \\
\hline $22 / 06 / 11$ & $17: 40$ & ELA & 65.0 & SEY37 & V9TP & 3593 & 16.6 & 13.5 & 5 & 0.4 \\
\hline $23 / 06 / 11$ & $17: 00$ & ELA & 62.0 & SEY37 & V9TP & 3595 & 16.6 & 15.4 & 1 & 0.1 \\
\hline $24 / 06 / 11$ & $14: 05$ & ELA & 79.5 & SEY37 & V9TP & 3597 & 16.6 & $7.8^{*}$ & 3 & 0.4 \\
\hline $24 / 06 / 11$ & $14: 30$ & ELA & 77.0 & SEY37 & V9P & 3621 & 16.6 & 11.4 & 1 & 0.1 \\
\hline $23 / 06 / 11$ & $17: 45$ & TRI & 30.5 & SEY37 & V9P & 3617 & 16.6 & 10.8 & 0 & 0.0 \\
\hline $23 / 06 / 11$ & 18:00 & TRI & 28.0 & SEY37 & V9P & 3618 & 16.6 & 10.8 & 0 & 0.0 \\
\hline $24 / 06 / 11$ & $13: 52$ & TRI & 30.0 & SEY37 & V9P & 3619 & 16.6 & 10.1 & 1 & 0.1 \\
\hline $24 / 06 / 11$ & $14: 15$ & TRI & 30.5 & SEY37 & V9P & 3620 & 16.6 & 13.5 & 3 & 0.2 \\
\hline $13 / 04 / 12$ & $14: 48$ & ELA & 63.5 & SEY41 & V9AP & 4668 & 21.4 & $27.7 *$ & 36 & 1.3 \\
\hline $14 / 04 / 12$ & $08: 56$ & ELA & 28.5 & SEY41 & V9P & 7072 & 21.4 & 29.8 & 75 & 2.5 \\
\hline $14 / 04 / 12$ & $11: 30$ & ELA & 30.0 & SEY41 & V9P & 7073 & 21.4 & 29.8 & 77 & 2.6 \\
\hline $14 / 04 / 12$ & $18: 32$ & TRI & 29.0 & SEY41 & V9AP & 4672 & 21.4 & 29.5 & 17 & 0.6 \\
\hline $13 / 04 / 12$ & $16: 55$ & TRI & 33.5 & SEY41 & V9P & 7069 & 21.4 & $27.6^{*}$ & 93 & 3.4 \\
\hline $14 / 04 / 12$ & $07: 40$ & TRI & 30.5 & SEY41 & V9P & 7070 & 21.4 & 29.9 & 50 & 1.7 \\
\hline $14 / 04 / 12$ & 08:02 & TRI & 30.0 & SEY41 & V9P & 7071 & 21.4 & 29.9 & 30 & 1.0 \\
\hline $18 / 06 / 11$ & $14: 00$ & ELA & 30.5 & SEY43 & V9P & 3586 & 4.4 & 3.4 & 1 & 0.3 \\
\hline $19 / 06 / 11$ & $10: 59$ & ELA & 57.0 & SEY43 & V9P & 3588 & 4.4 & 3.3 & 2 & 0.6 \\
\hline $19 / 06 / 11$ & $11: 20$ & ELA & 32.0 & SEY43 & V9TP & 3590 & 4.4 & 3.3 & 1 & 0.3 \\
\hline $19 / 06 / 11$ & $11: 45$ & ELA & 34.0 & SEY43 & V9P & 3606 & 4.4 & 1.9 & 1 & 0.5 \\
\hline $19 / 06 / 11$ & $13: 15$ & ELA & 61.5 & SEY43 & V9TP & 3607 & 4.4 & 2.3 & 1 & 0.4 \\
\hline $19 / 06 / 11$ & $13: 45$ & ELA & 79.0 & SEY43 & V9TP & 3610 & 4.4 & 4.3 & 1 & 0.2 \\
\hline $18 / 06 / 11$ & $14: 35$ & TRI & 32.0 & SEY43 & V9P & 3611 & 4.4 & 4.2 & 3 & 0.7 \\
\hline $18 / 06 / 11$ & $14: 45$ & TRI & 30.5 & SEY43 & V9P & 3612 & 4.4 & 4.2 & 2 & 0.5 \\
\hline $18 / 06 / 11$ & $14: 55$ & TRI & 34.0 & SEY43 & V9P & 3613 & 4.4 & 4.2 & 2 & 0.5 \\
\hline $18 / 06 / 11$ & $15: 15$ & TRI & 26.5 & SEY43 & V9P & 3614 & 4.4 & 2.8 & 0 & 0.0 \\
\hline $18 / 06 / 11$ & $15: 30$ & TRI & 30.5 & SEY43 & V9P & 3615 & 4.4 & 4.2 & 3 & 0.7 \\
\hline $26 / 04 / 12$ & $11: 34$ & ELA & 64.0 & SEY59 & V9AP & 4680 & 85.2 & $16.8^{*}$ & 7 & 0.4 \\
\hline $26 / 04 / 12$ & $11: 57$ & ELA & 61.0 & SEY59 & V9AP & 4682 & 85.2 & $17.0^{*}$ & 22 & 1.3 \\
\hline $26 / 04 / 12$ & $13: 37$ & ELA & 44.5 & SEY59 & V9AP & 4684 & 85.2 & $16.7 *$ & 17 & 1.0 \\
\hline $26 / 04 / 12$ & $17: 50$ & ELA & 35.0 & SEY59 & V9AP & 4686 & 85.2 & 84.9 & 206 & 2.4 \\
\hline $26 / 04 / 12$ & $10: 15$ & TRI & 30.5 & SEY59 & V9AP & 4674 & 85.2 & $57.9 *$ & 17 & 0.3 \\
\hline $26 / 04 / 12$ & $10: 27$ & TRI & 35.0 & SEY59 & V9AP & 4676 & 85.2 & $66.4^{*}$ & 23 & 0.3 \\
\hline $26 / 04 / 12$ & $10: 33$ & TRI & 32.0 & SEY59 & V9AP & 4678 & 85.2 & $64.4^{*}$ & 16 & 0.2 \\
\hline
\end{tabular}




\section{Residency}

TRT at FADs for the rainbow runner ranged between 1.9 to 84.9 days and 2.8 and 66.4 days for the oceanic triggerfish. The large range in residency was not always indicative of natural behaviour as observations were often terminated prematurely due to either fishing operations, which resulted in the capture of the FAD-associated fish, or equipment failure (Table 1 ). A high residency index score was obtained for both oceanic triggerfish $(0.75 \pm 0.28$, mean \pm $\mathrm{SD})$ and rainbow runner $(0.75 \pm 0.25$, mean $\pm \mathrm{SD})$. Kaplan-Meier survival curves revealed considerable overlaps in confidence intervals for both species suggesting that they displayed similar residency patterns (Fig. 2). This was confirmed by the log-rank test of comparison as no significant difference was observed between the survival functions of the two species (censored curve: $\chi 2=0.8, \mathrm{df}=1, \mathrm{p}=0.36$, uncensored: $\chi 2=0.9$, df $=1, \mathrm{p}=0.344$ ). KaplanMeier survival curves considering the censored TRT did not reach 0 as the longest TRTs were censored due to equipment failure and suggest that the maximum residence time of rainbow runner and oceanic triggerfish was underestimated. The Median values from the Kaplan-Meier survival curves with censoring was 59 days for oceanic triggerfish but could not be determined for rainbow runner as the curve did not decrease below 0.5 due to the censoring of the longest TRTs. Instead, the survivorship at $60 \%$ was used for comparisons. The Kaplan-Meier survival curves with censoring estimated that $60 \%$ of oceanic triggerfish and rainbow runner remained associated with FADs for approximately 30 days and 25 days respectively (Fig. 2(b)). Using uncensored data, the estimation was reduced to approximately 15 days for oceanic triggerfish and 17 days for rainbow runner (Fig. 2(a)). Mean residence time estimation using the survival regression model on censored data was 65 days for oceanic triggerfish and 94 days for rainbow runner. The overall mean TRT (no regression model) was of 21.01 days ( \pm 17.59 SD) for oceanic triggerfish and 23.5 days ( $\pm 21.80 \mathrm{SD}$ ) for rainbow monnar

(a)

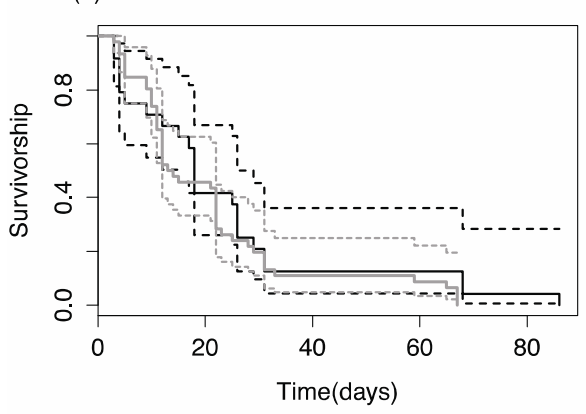

(b)

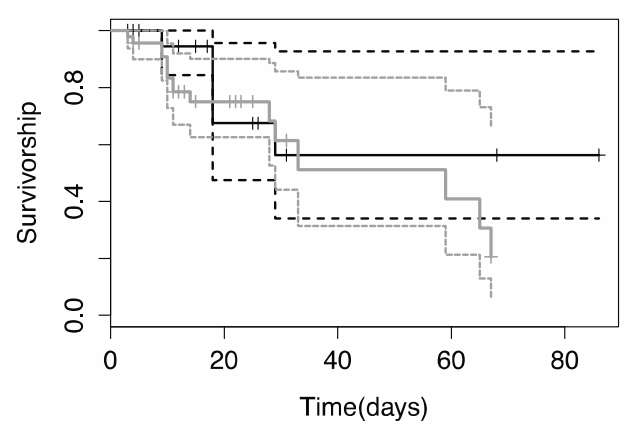

255

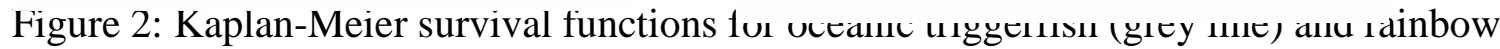
runner (black line) for (a) all TRTs and (b) natural departure TRTs and censored TRTs. Horizontal ticks indicate censored data points. Dotted lines represent 95\% confidence interval.

\section{Temporal patterns in association}

In general, both species remained within the reception range of the receiver throughout most of the day (Figs. 3,4 ). Gaps in detections indicate when individuals were out of the reception range, away from the FADs (Fig. 3,4, S1). 


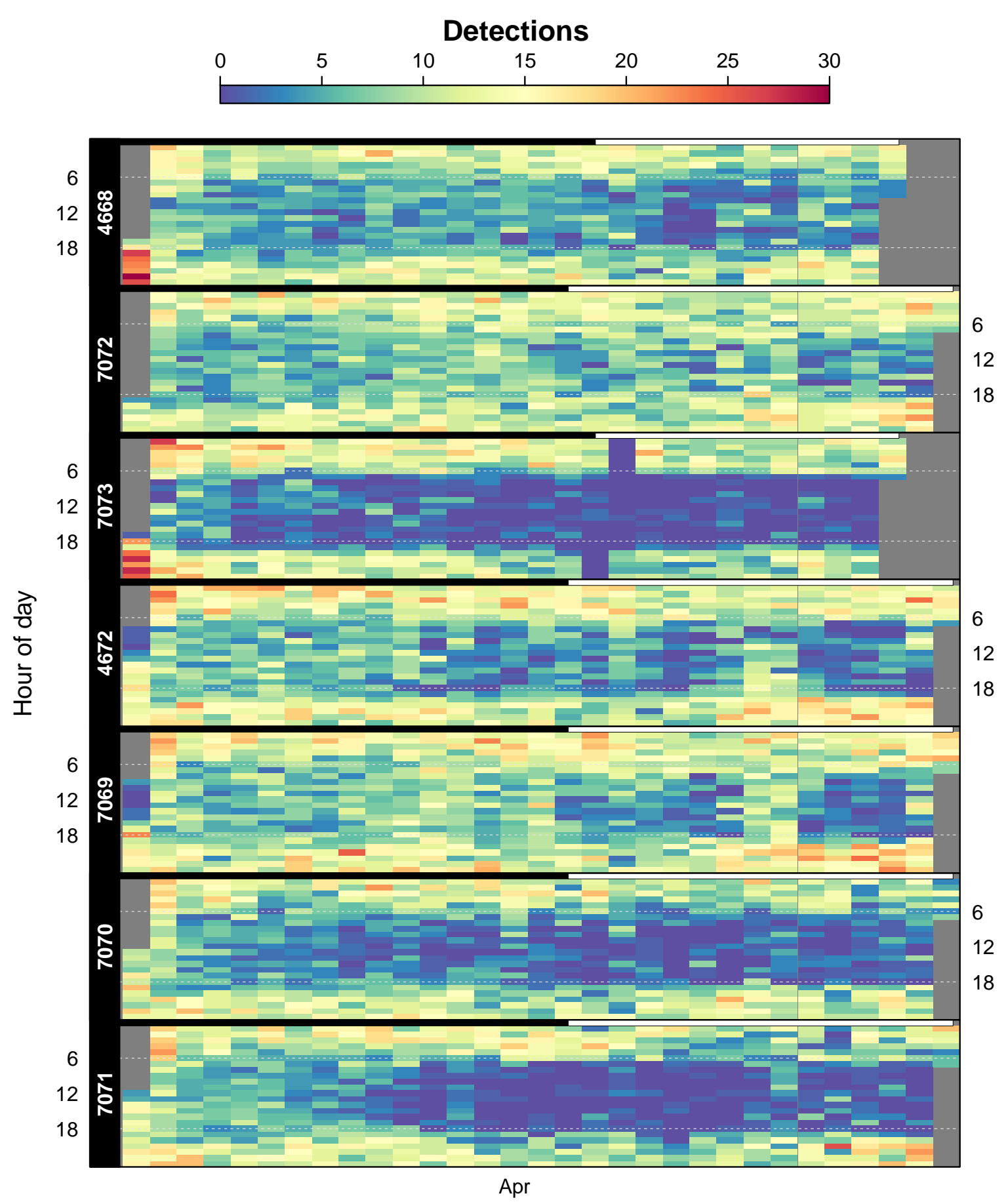

268 Figure 3: Examples of hourly detection chronogram for rainbow runner (ID\# 4668, 7072, 269 7073) and oceanic triggerfish (ID\# 4672, 7069, 7070, 7071) at FAD SEY41. Each strip 270 illustrates the hourly detections of an individual (ID\# on the left). Hour of the day is on the y271 axis and time (days) on the x-axis. The scale denotes the corresponding number of detections. 


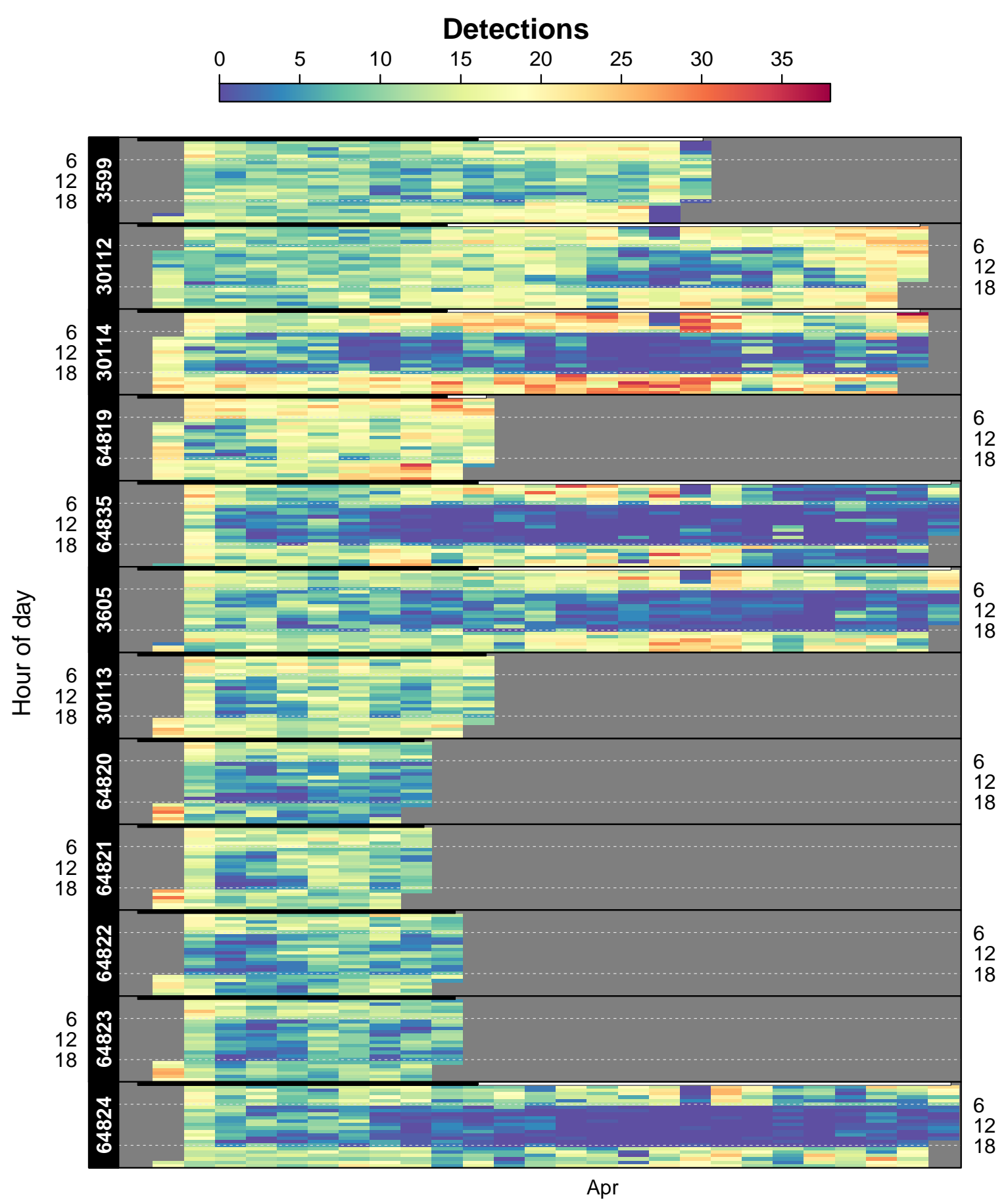

Figure 4: Examples of hourly detection chronogram for oceanic triggerfish (ID\# 3605, 30113, 274 64820, 64823, 64824, 64822, 64821) and rainbow runner (ID\# 30112, 64835, 64819, 30114, 275 3599) at FAD MAY42. Each strip illustrates the hourly detections of an individual (ID\# on 276 the right). Hour of the day is on the y-axis and time (days) on the x-axis. The scale denotes 277 the corresponding number of detections. 

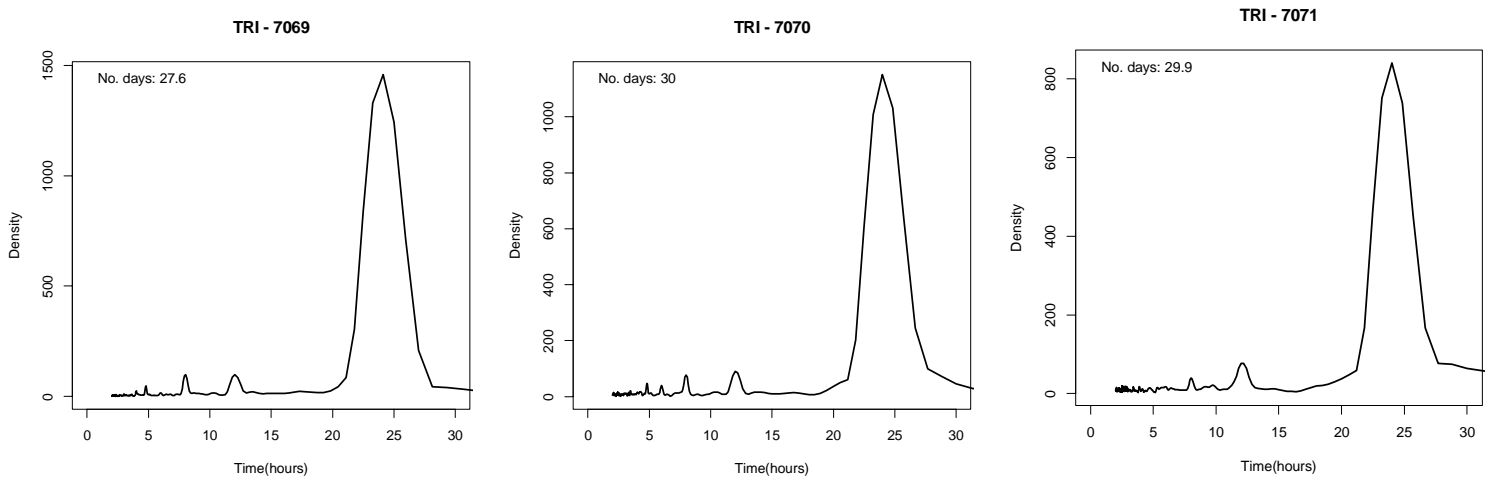

281
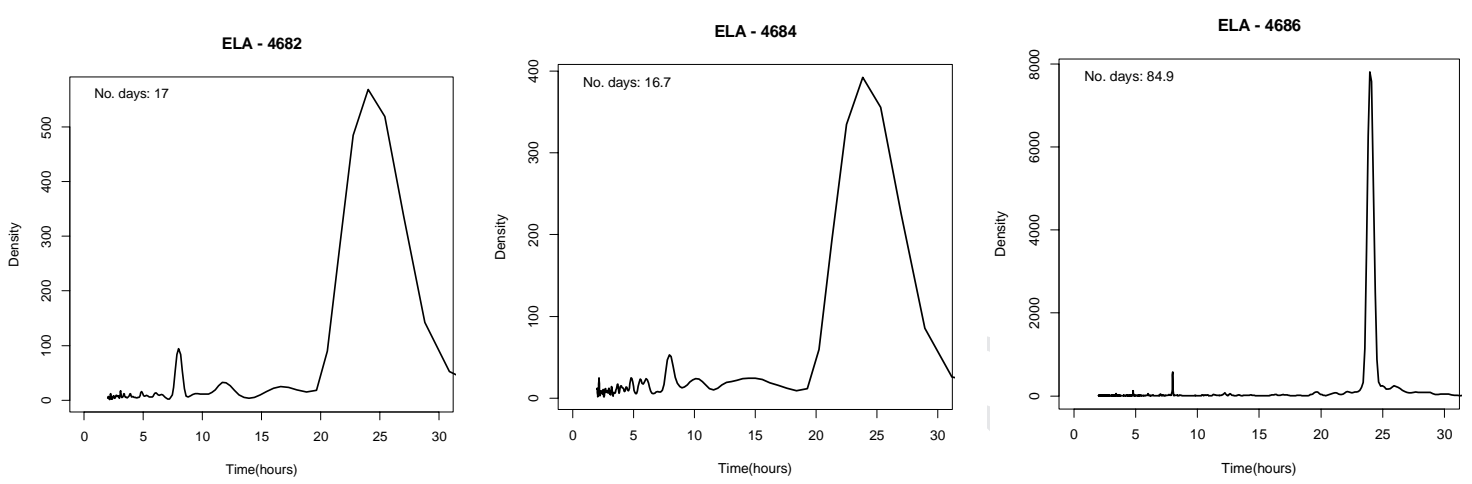

Figure 5: Examples of fast fourier transform (FFT) spectral densities for three oceanic triggerfish (top) and three rainbow runner (bottom) at drifting FADs. 

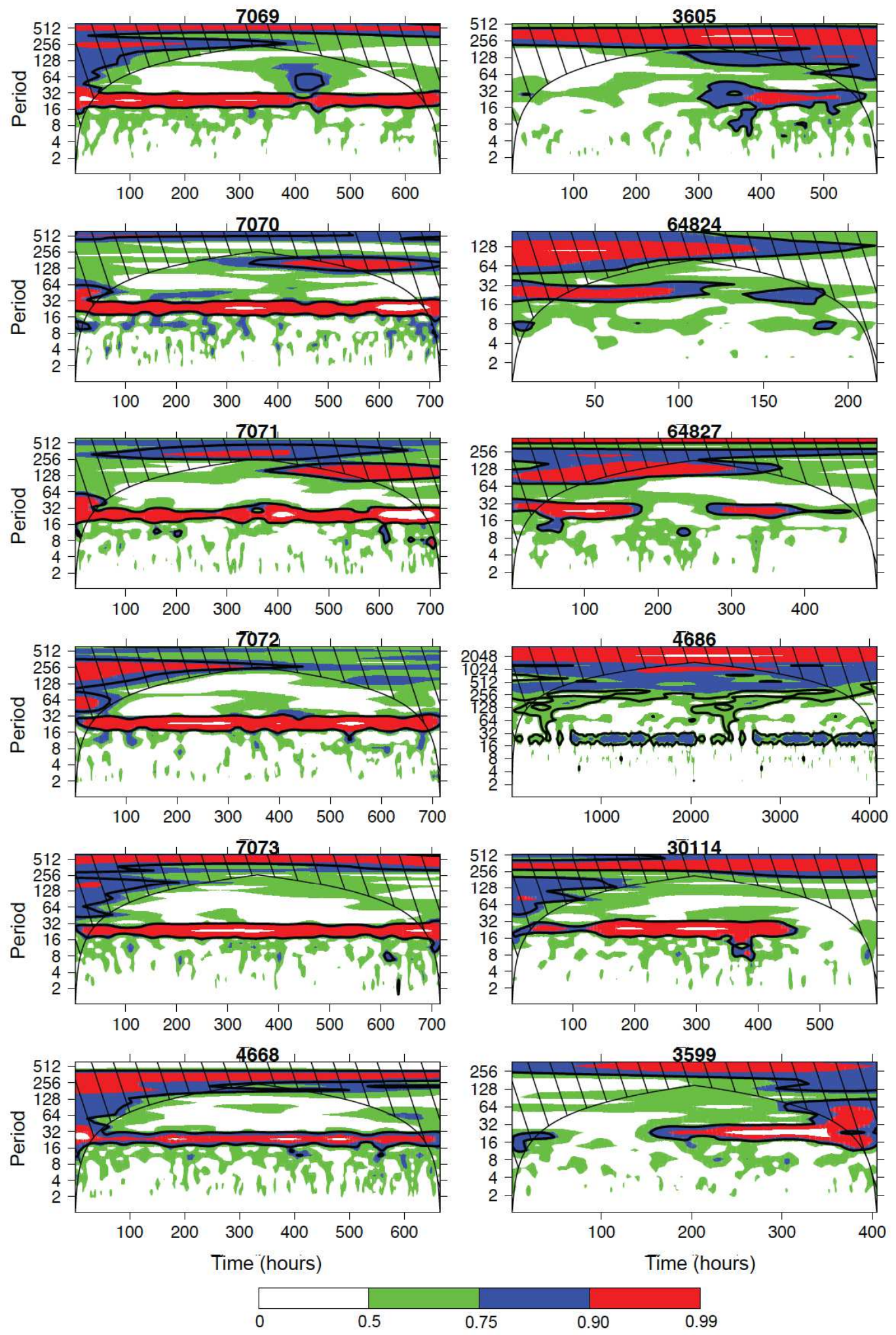

289 Figure 6: Wavelet spectrum examples of oceanic triggerfish (Top; ID\# 7069, 7070, 7071,

290 3605, 64824, 64827) and rainbow runner (bottom; ID\# 7072, 7073, 4668, 4686, 30114, 3599)

291 using Morlet wavelet of hourly detections showing persistent diel behaviour (left) and

292 intermittent diel behaviour (right). Barred area represents the cone of influence (COI). Values

293 inside the COI cannot be interpreted due to edge effects. The thick black contour lines

294 represent $95 \%$ confidence level and the scale bar represents the intensity of the time-

295 frequency space over time. 
Temporal patterns in association using FFT spectral analysis revealed a strong periodicity in the association of both species at FADs with a distinct peak at $24 \mathrm{~h}$ (Fig. $\underline{5}$ ). This pattern was observed for all analysed individuals of both species (rainbow runner $n=18$, oceanic triggerfish $n=40$ ) with sufficient data ( $>5$ days), indicating the presence of a distinct diel pattern in their associative behaviour. This diel pattern is characterised by a stronger association during the night and excisions away from the FAD during the day.

Moreover, the $24 \mathrm{~h}$ periodicity was clear on the wavelet spectrograms with a significant signal (Fig. 6). However, intraspecific variability in the persistence of the $24 \mathrm{~h}$ periodicity was apparent (Fig. 6). Examples in Fig. $\underline{6}$ illustrates different patterns in the persistence of periodicity; some individuals exhibited continuous periodicity (oceanic triggerfish: ID\# 7079, 7070, 7071; rainbow runner: ID\# 7072, 7073, 4668) throughout their residency at FADs while others displayed intermittent periods of periodicity (oceanic triggerfish: ID\# 3605, 64824, 64827; rainbow runner: ID\# 4686, 30114, 3588). These observed differences in pattern were not FAD specific, but rather reflects individual behavioural variability.

Overall, $82 \%$ of tagged oceanic triggerfish performed excursions while all tagged rainbow runner performed at least one excursion (Table 1 ). The distributions of the excursion index was not unimodal (Fig.7). A second mode was observed in the excursion index distributions of rainbow runner and to a lesser extent for oceanic triggerfish. This indicates a different modality in the associative behaviour; some individuals performed $\sim 2-3$ times more excursions per day than their conspecifics (Fig.7). Rainbow runner performed more excursions per day than oceanic triggerfish; the mean excursion index was of $0.86( \pm 0.8 \mathrm{SD})$ for oceanic triggerfish and 1.31 ( $\pm 1.1 \mathrm{SD})$ for rainbow runner. The mean duration of excursions was of 2.0 hours $( \pm 1.6 \mathrm{SD})$ for oceanic triggerfish and 2.4 hours $( \pm 2.2 \mathrm{SD})$ for
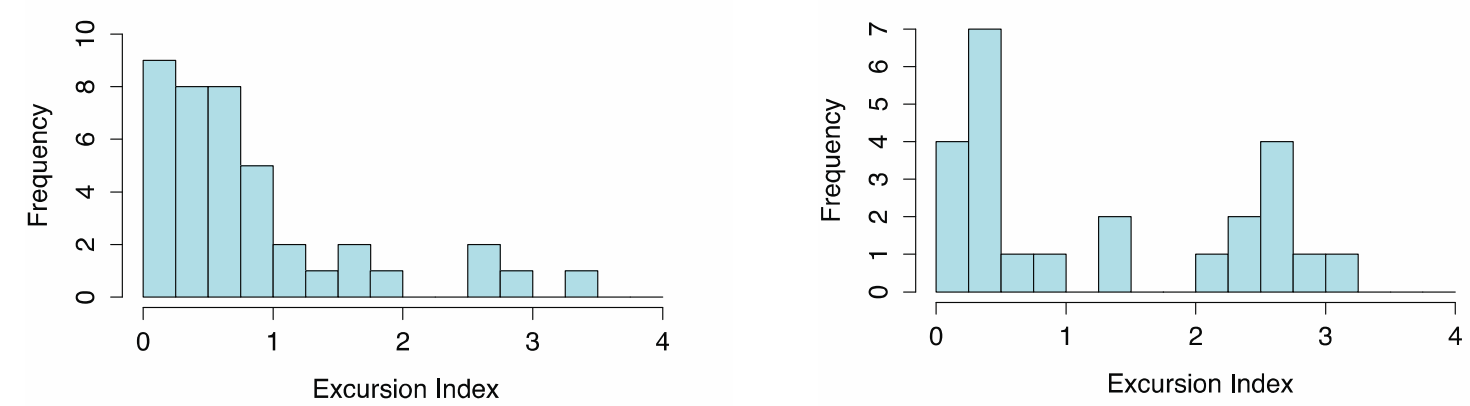

Figure 7: Frequency histogram distributions of excursion index for oceanic triggerfish (left) 


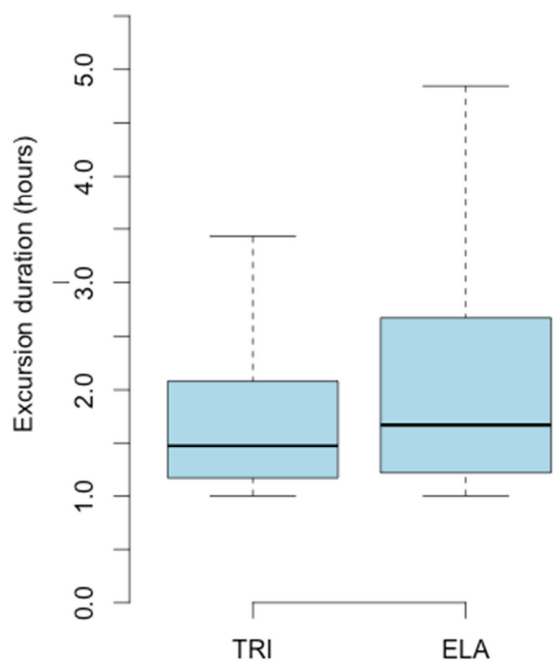

327 Figure 8: Box and whisker plots of excursion durations of oceanic triggerfish (TRI) and 328 rainbow runner (ELA).

The distribution and durations of excursions were then examined at a $24 \mathrm{~h}$ scale at all the FADs. The heatmap (Fig. 9) indicates that the majority of the excursion activity (departures and returns) occurred during the daytime for both species (rainbow runner: $72.5 \%$, oceanic triggerfish: $81.2 \%$ ). A sharp increase in excursion departure occurred at sunrise and a decrease at sunset irrespective of the excursion duration. While excursion durations were typically short (Fig. 8), the pattern observed for longer excursions was distinct; for both species, there was a linear decrease in the longer excursion which ended before sunset (Fig. 9). 

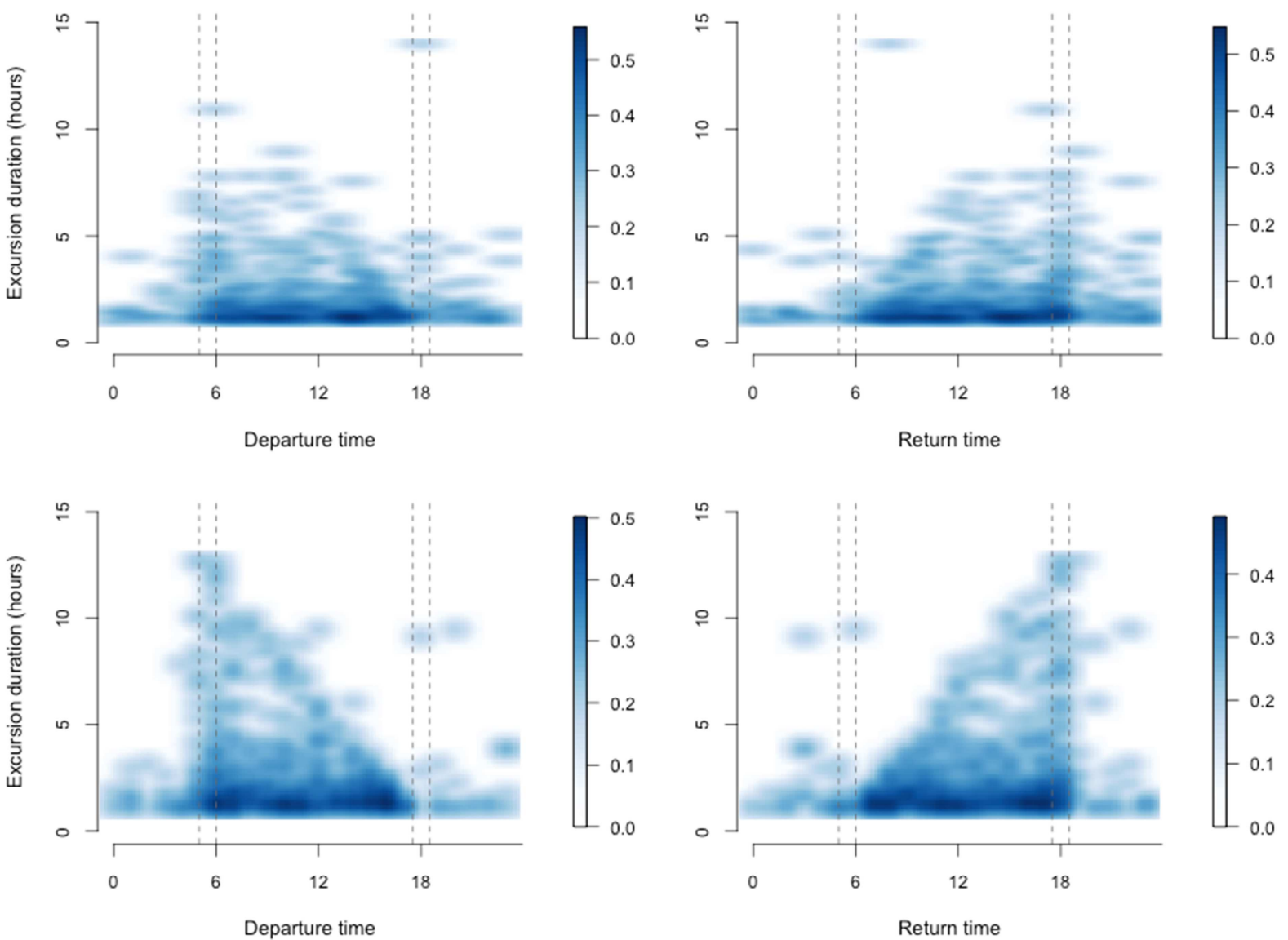

Figure 9: Heatmap of departure and return time (local time) of excursions with corresponding durations for oceanic triggerfish (top) and rainbow runner (bottom) at all the FADs. Densities are represented on the scale bars. Areas between doted lines represent sunrise and sunset hours.

The variability in the associative behaviour amongst individuals of the two species as well as temporal variability of individuals during their association is depicted in Figs. 3,4 and 6. While some detection gaps may appear to be synchronous, they do not appear to be systematic amongst individuals of the same species. The clustering analysis revealed that there was no clear species-specific grouping in the associative patterns; some triggerfish displayed more similar associative behaviours to rainbow runner than their conspecifics (Fig. 


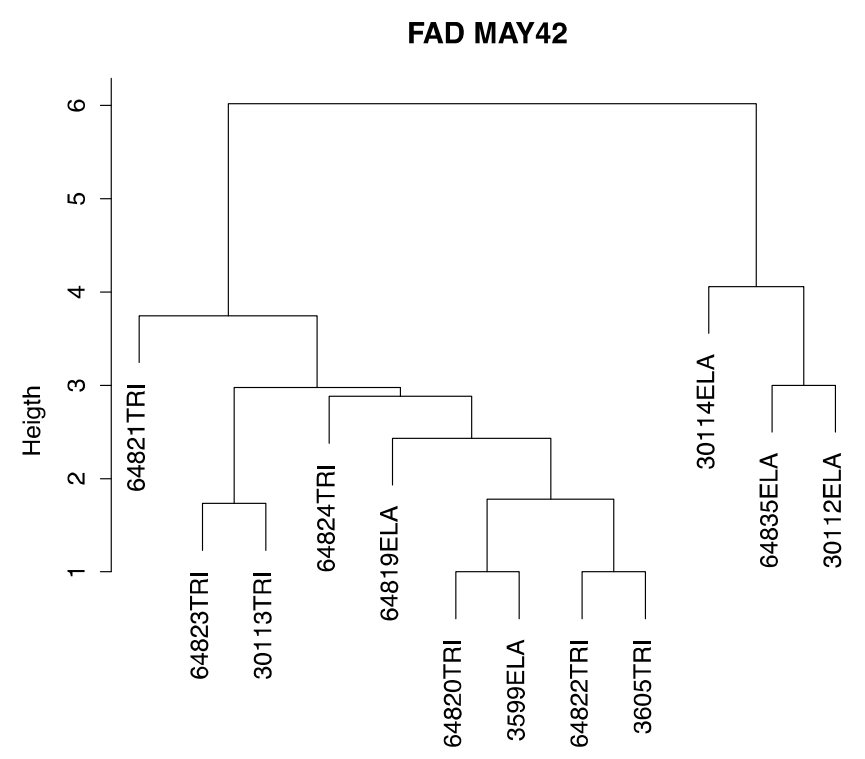

355

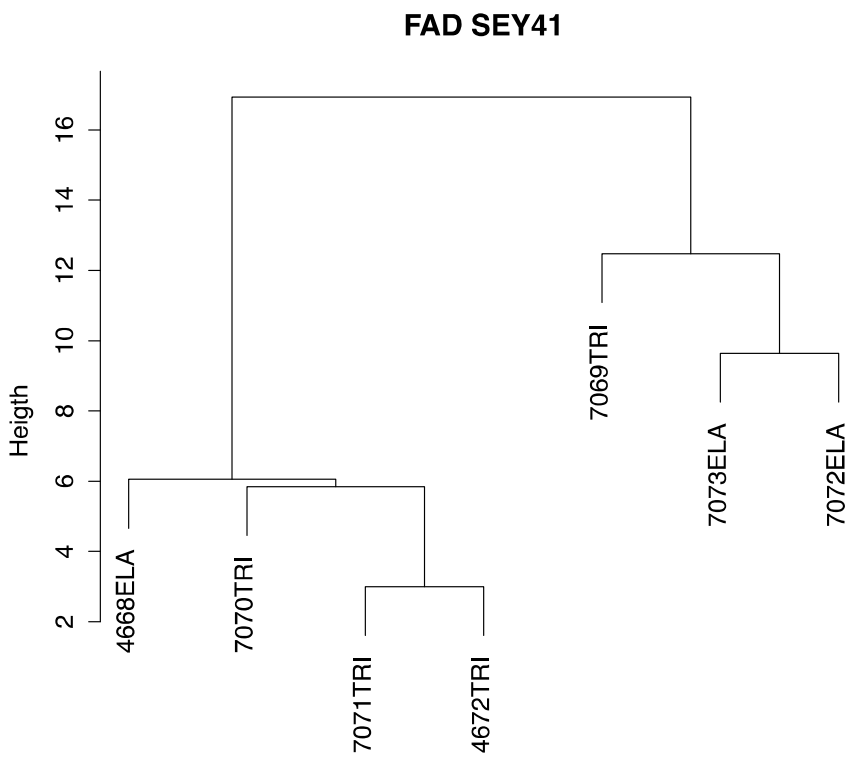
SEY41 and MAY42. End nodes are denoted by ID number and species code (TRI = oceanic triggerfish, ELA = rainbow runner). 
368 Discussion

\section{Residency at FADs}

370 Both rainbow runner and oceanic triggerfish remained associated with the same floating

371 object for extended periods. The maximum residence time at the same drifting FAD recorded

372 during this study (i.e. 84.6 days for rainbow runner and 66.4 days for oceanic triggerfish )

373 represents the highest values ever reported for FAD-associated fishes. [Dagorn2007] was the

374 first study to tag both tuna and non-target species (121 fish of 7 different species) at drifting

375 FADs. Their study provided a general mean residence time for yellowfin tuna (mean: 1.04

376 days, $\pm 2.23 \mathrm{SD}$ ), skipjack tuna (mean: 0.91 days, $\pm 2.17 \mathrm{SD}$ ), bigeye tuna (mean: 1.43 days,

$377 \pm 1.46 \mathrm{SD}$ ) silky sharks (mean: 5.33 days, $\pm 3.16 \mathrm{SD}$ ), wahoo (mean: 1.57 days, $\pm 2.73 \mathrm{SD}$ ),

378 dolphinfish (mean: 3.96 days, $\pm 3.86 \mathrm{SD}$ ), silky sharks (mean: 5.33 days, $\pm 3.16 \mathrm{SD}$ ) and

379 oceanic triggerfish (mean: 12.49 days, \pm 6.08 SD), while [Filmalter2015] reported a mean

380 residence time of 14.03 days at drifting FADs for silky sharks. [Taquet2007a] reported that

381 the mean residence time of dorado at drifting FADs was of 6.25 days (median of 5.09 days).

382 The overall mean residence time in this study was 21.03 days for oceanic triggerfish and 23.5

383 days for rainbow runner which is considerably longer than what was reported above. No

384 previous investigations have reported on the residency of rainbow runners at drifting FADs.

385 While the 'raw' mean residence time provides some general indication of residency, it is

386 biased by observation lengths and truncations. Indeed, the mean residence time estimation from the regression model of censored data was considerably higher with 65 days for oceanic triggerfish and 94 days for rainbow runner. Using mean values as a descriptor of the survivorship can be misleading due to the skewed nature of the survival functions. It is therefore recommended that median values from Kaplan-Meier survival curves (with censoring) are jointly reported in order to allow appropriate comparisons of residency time estimations between studies. The residency index also indicated high residency with scores above 0.75 being comparable to those obtained for resident reef species [Alos 2012a, Mason2010, Toole2011]. The ecological trap hypothesis suggests that massive seeding of drifting FADs could have a negative impact on the populations of associated species [Hallier2008c, Marsac2000]. To date, there no clear evidence in favour of this hypothesis and the few studies that have investigated this topic have focused on tunas [Hallier2008c, Menard2000, Robert2014]. In a hypothetical ecological trap scenario, the impacts on populations of oceanic triggerfish and rainbow runner, due to their long residency, should be more prominent. However, as highlighted by [Robert2014], demonstrating the presence of an ecological trap scenario is not trivial and requires baseline information on biological parameters (e.g. physiological condition, reproductive success, etc). While the two studied species could be good candidates to study the ecological trap hypothesis, the difficulty remains in finding a control to test this hypothesis.

\section{Temporal patterns in association}

408 Diel pattern in association with FADs have been reported for yellowfin, bigeye and skipjack tuna at anchored FADs [Holland1990, Marsac1998, Ohta2005, Yuen1970] and drifting FADs [Forget2015, Schaefer2013, Matsumoto2014] with a closer association during the day.

411 Similarly, silky sharks displayed a stronger association during the day [Filmalter2015, 412 Forget2015] while no clear pattern was found for dorado at FADs [Taquet2007a]. A distinct 413 diel pattern in the associative behaviour with FADs was observed here for oceanic triggerfish 
416

417

418

419

420

421

422

423

424

425

426

427

428

429

430

431

432

433

434

435

436

437

438

439

440

441

442

443

444

445

446

447

448

449

450

451

452

453

454

455

456

457

458

459

460

461

462

463

464 increased their home range as they performed excursions away from the FAD, out of the receiver's reception range. This diel pattern is more commonly observed in reef associated species [Koeck2014, Alos2011]. The studies mentioned above have suggested that nocturnal feeding behaviour drives the switch in the associative mode of tunas and silky shark as they move away from the FAD and feed on the deep scattering layer. An opposing diel pattern in the pelagic realm observed for oceanic triggerfish and rainbow runner is intriguing and may reflect differences in foraging strategy or predator avoidance mechanisms. Information on their vertical movement behaviour to investigate the depth strata usage and feeding ecology may help elucidate this different diel associative pattern.

Ambient light intensity appears to be the stimulus triggering the onset and end of the associative modes. After sunrise, the two species typically increase their home range and perform excursions away from the FAD. The average excursion duration of oceanic triggerfish $(2.05 \mathrm{~h})$ and rainbow runner $(2.45 \mathrm{~h})$ suggests that individuals, generally, do not venture far from the FAD. Considering a swimming speed of 1 body length per sec, the maximum home range size of the two species (assuming constant speed and a linear movement away from FAD) during a typical excursion could range between 1.1 and $2.2 \mathrm{~km}$. During an active tacking experiment conducted on FAD SEY41, the maximum measured distance of oceanic triggerfish away from the FAD (during an excursion), while tracking a silky shark, was $800 \mathrm{~m}$ [Filmalter2015]. The homing abilities and mechanisms used by fish to return and relocate FADs has intrigued scientists for many years. Tunas perform extended nocturnal excursions away from FADs and active tracking studies have reveiled that, during this time, they can be found within a radius of 5-10 km from the FAD [Dagorn2000c, Holland1990, Matsumoto2014]. The ability of tuna to relocate FADs from such large distances demonstrates their navigational and homing capabilities [Holland1990]. [Girard2007] investigated the homing abilities of dorado through displacement experiments and acoustic telemetry and reported successful homing up to $1.6 \mathrm{~km}$ from the FAD. [Filmalter2015] actively tracked a silky shark at a drifting FAD during one day and reported a maximum straight line distance of $1.2 \mathrm{~km}$ between the shark and the FAD. [Ibrahim1990] investigated the ability of various small $(<40 \mathrm{~cm}$ TL) FAD-associated species to relocate FADs by displacing fish tagged with floats at various distances from the FAD and reported that a maximum homing distance of $180 \mathrm{~m}$. In their pioneer study, [Hunter1967] looked into the homing ability of oceanic triggerfish by tagging and releasing 10 individuals at 7.5, 15 and $30.5 \mathrm{~m}$ from their original drifting $\log$. None of the fish released at $30.5 \mathrm{~m}$ returned to the original log. The authors concluded that the greatest distance was outside the visual range of the fish and thus the fish could not orientate towards it. The results from this study, however, indicate that both oceanic triggerfish and rainbow runner are capable of returning to the FAD after several hours out of its visual range (several hundred meters) and as highlighted by previous studies [Dempster2003, Ibrahim1990] vision cannot be of aid from such large distances. It is conceivable that other sensory cues, such as sounds generated by the floating object or the fishes in close proximity to it, may be used by FAD associated species for homing, however, the hearing capabilities of pelagic fish and its use for navigation remains unclear [Dempster2003].

The motive of excursions away from FADs displayed by tunas, dorado and silky shark has largely been attributed to foraging activities [Filmalter2015, Holland1990, Taquet2007a]. Foraging could also be the primary motive causing the increase in home range of the two studied species. If so, the fact that excursions occur during the day suggests that the two species have a different foraging strategy to that of tunas and silky sharks; which tend to be more active nocturnally. [Klima1971] proposed that floating objects act as a spatial reference point that fish use to orientate in an otherwise unstructured environment. The two species 
465

466

467

468

469

470

471

472

473

474

475

476

477

478

479

480

481

482

483

484

485

486

487

488

489

490

491

492

493

494

495

496

497

498

499

500

501

502

503

504

505

506

507

508

509

510

511

512 may temporarily increase their home range for feeding while using the FAD as a reference point.

The cluster analysis revealed that there was no species-specific grouping of the associative behaviour at FADs. Variability was observed in the associative behaviour amongst individuals of the two species and the fact there was no systematic synchronisation in absences from FAD amongst individuals suggests that oceanic triggerfish and rainbow runner do not form unique monospecific schools at FADs and are more likely to form several sub schools. Some individuals of the two species performed 2 to 3 times more excursions per unit time than their conspecifics. This intraspecific difference in behaviour was more apparent for rainbow runner and suggests the presence of a different behavioural mode. The fact that individuals at the same FAD experiencing the same abiotic and biotic environmental conditions display different behaviours indicates behavioural polymorphism. Behavioural variability in fishes has been observed at fine scales under controlled laboratory conditions [Raimondi1990] and has also been used to explain differences in large scale movements, such as migration [Kerr2009]. Explaining behavioural variability is challenging as the interplay between genetic variability, historical shifts in selection pressures and adaptive behaviour is hard to disentangle. Nevertheless, it is conceivable that foraging competition amongst numerous aggregated individuals (several hundreds at a single FAD; personal observation), within a restricted spatial sphere could favour these different behavioural modes.

Temporal variability in associative behaviour was apparent for both species. Wavelet analysis provided additional information on the persistence of diel patterns. Periods (days) when diel behaviour were less distinct were apparent as gaps in the periodicity signal were observed. Interestingly, periods with altered associative behaviour were sometimes synchronised amongst individuals suggesting a change in behaviour that could be a response to a particular stimulus of biotic or abiotic nature. In order to resolve which factors can influence the associative behaviour, information on biotic and abiotic variables should be collected simultaneously during experiments. More specifically, biotic factors, such as prey and predator density and details on the species assemblage, and abiotic factors, such as thermal structure of water column, FAD densities, would aid in understanding how such factors that can influence associative behaviour.

\section{Conclusion}

Oceanic triggerfish and rainbow runner have remarkably similar behavioural patterns in their association with FADs. This suggests that the convergence of their behaviour has risen from similar selective pressures and, hence, the two species are likely to have similar motives in associating with floating objects. More data on the ecology of the two species are required to pinpoint the exact motivations driving their behaviour. The long residence times observed for the two species implies that they are susceptible to high fishing effort on FADs. As such, key biological parameters and data to determine their ecological role in the pelagic ecosystem are need to model increased fishing mortality linked to the FAD based tuna fishery. It must however be noted that obtaining a metric of natural departure from FADs is challenging as it requires large effort, but, nevertheless, it remains a key parameter for modelling approaches to estimate direct and indirect impacts of FADs on the pelagic ecosystem.

\section{Acknowledgments}

This study was carried out with financial support from the Commission of the European Communities, specific RTD programme of Framework Programme 7, 'Theme 2 - Food, 
513 Agriculture, Fisheries and Biotechnology', through the research project MADE (Mitigating

514 adverse ecological impacts of open ocean fisheries), contract \#210496. This work does not

515 necessarily reflect the Commission's views and in no way anticipates its future policy in this

516 area. The work was also financially supported by the International Seafood Sustainability

517 Foundation (www.iss-foundation.org) under its Bycatch Mitigation Project.

\section{Compliance with ethical standards}

520

521

\section{Conflict of interest}

522

523

524

The authors declare that they have no conflicts of interest.

\section{Ethical approval}

525

526

527

528

529

\section{References}

530

531

532

533

534

All applicable international, national, and/or institutional guidelines for the care and use of animals were followed.

535

536

537

538

539

540

541

542

543

544

545

[Afonso et al. 2012] Afonso, Pedro and Graça, Gonçalo and Berke, Gregory and Fontes, Jorge, "First observations on seamount habitat use of blackspot seabream (Pagellus bogaraveo) using acoustic telemetry", Journal of Experimental Marine Biology and Ecology 436-437 (2012), pp. 1--10.

[Alós et al. 2011] Alós, Josep and March, David and Palmer, Miquel and Grau, Amalia and Morales-Nin, Beatriz, "Spatial and temporal patterns in Serranus cabrilla habitat use in the NW Mediterranean revealed by acoustic telemetry", Marine Ecology Progress Series 427, August (2011), pp. 173--186.

[Alós et al. 2012] Alós, Josep and Cabanellas-Reboredo, Miguel and March, David, "Spatial and temporal patterns in the movement of adult two-banded sea bream Diplodus vulgaris (Saint-Hilaire, 1817)", Fisheries Research 115-116 (2012), pp. 82--88.

[Amande et al. 2011] Amande, Monin Justin and Ariz, Javier and Chassot, Emmanuel and de Molina, Alicia Delgado and Gaertner, Daniel and Murua, Hilar..., "Bycatch of the European purse seine tuna fishery in the Atlantic Ocean for the 2003-2007 period", Aquatic Living Resources 23, 4 (2011), pp. 353--362.

[Amandè et al. 2011] Amandè, J and Ariz, Javier and Chassot, Emmanuel and Chavance, Pierre and Molina, Alicia Delgado De and Gaertner, Daniel ..., "By-catch and discards of the European purse seine tuna fishery in the Atlantic Ocean: estimation and characteristics for 2008 ...", Collect. Vol. Sci. Pap. ICCAT 66 (2011), pp. 2113--2120.

[Bakun 2006] Bakun, Andrew, "Frentes y remolinos como estructuras clave en el habitat de las larvas de peces marinos: oportunidad, respuesta adaptativa y v...", Scientia Marina 70, S2 (2006), pp. 105--122. 
[Barnett et al. 2012] Barnett, Adam and AbrantesKá, Kátya G. and Seymour, Jamie and Fitzpatrick, Richard, "Residency and spatial use by reef sharks of an isolated seamount and its implications for conservation", PLoS ONE 7, 5 (2012), pp. 1--12.

[Capello et al. 2015] 1. Capello M, Robert M, Soria M, Potin G, Itano D. A Methodological Framework to Estimate the Site Fidelity of Tagged Animals Using Passive Acoustic Telemetry. 1-19 (2015).

[Castro et al. 2002] Castro, José J. and Santiago, Jóse A. and Santana-Ortega, Ana T., "A general theory on fish aggregation to floating objects: An alternative to the meeting point hypothesis", Reviews in Fish Biology and Fisheries 11, 3 (2002), pp. 255--277.

[Dagorn and Fréon 1999] Dagorn, Laurent and Fréon, Pierre, "Tropical tuna associated with floating objects: a simulation study of the meeting point hypothesis", Canadian Journal of Fisheries and Aquatic Sciences 56, 6 (1999), pp. 984--993.

[Dagorn et al. 2000] Dagorn, Laurent and Josse, Erwan and Bach, Pascal, "Individual differences in horizontal movements of yellowfin tuna (Thunnus albacares) in nearshore areas in French Polynesia, d...", Aquatic Living Resources 13, 4 (2000), pp. 193--202.

[Dagorn et al. 2007a] Dagorn, Laurent and Holland, Kim N. and Itano, David G., "Behavior of yellowfin (Thunnus albacares) and bigeye (T. obesus) tuna in a network of fish aggregating devices (FADs)", Marine Biology 151, 2 (2007), pp. 595--606.

[Dagorn et al. 2007b] Dagorn, Laurent and Pincock, Doug and Girard, Charlotte and Holland, Kim and Taquet, Marc and Sancho, Gorka and Itano, David an..., "Satellitelinked acoustic receivers to observe behavior of fish in remote areas", Aquatic Living 312, 2007 (2007), pp. 307--312.

[Dagorn et al. 2013] Dagorn, Laurent and Holland, Kim N. and Restrepo, Victor and Moreno, Gala, "Is it good or bad to fish with FADs? What are the real impacts of the use of drifting FADs on pelagic marine ecosystems?", Fish and Fisheries 14, 3 (2013), pp. 391--415.

[Dempster and Kingsford 2003] Dempster, Tim and Kingsford, Michael J. Mj, "Homing of pelagic fish to fish aggregation devices (FADs): the role of sensory cues", Marine Ecology Progress Series 258, Kingsford 1999 (2003), pp. 213--222.

[Filmalter et al. 2015] Filmalter, J and Cowley, P and Forget, F and Dagorn, L, "Fine-scale 3-dimensional movement behaviour of silky sharks Carcharhinus falciformis associated with fish aggregating devices ...", Marine Ecology Progress Series 539, November (2015), pp. 207--223.

[Fiorellato et al. 2019] Fiorellato F, Pierre L, Geehan J. Review of the statistical data and fishery trends tropical tunas. 2019. 
[Fonteneau et al. 2000] Fonteneau, Alain and Pallarés, Pilar and Pianet, Renaud, "A worldwide review of purse seine fisheries on FADs", in Pêche thonière et dispositifs de concentration de poissons, Caribbean-Martinique, 15-19 Oct 1999 (, 2000), pp. 15--35.

609

610

611

612

613

614

615

616

617

618

619

620

621

622

623

624

625

626

627

628

629

630

631

632

633

634

635

636

637

638

639

640

641

642

643

644

645

646

647

648

649

650

[Fonteneau et al. 2013] Fonteneau, Alain and Chassot, Emmanuel and Bodin, Nathalie, "Global spatio-temporal patterns in tropical tuna purse seine fisheries on drifting fish aggregating devices (DFADs): Taking a ...", Aquatic Living Resources 26, August (2013), pp. 37--48.

[Forget et al. 2015] Forget, Fabien G. and Capello, Manuela and Filmalter, John David and Govinden, Rodney and Soria, Marc and Cowley, Paul D and Da..., "Behaviour and vulnerability of target and non-target species at drifting fish aggregating devices (FADs) in the tropical tuna ...", Canadian Journal of Fisheries and Aquatic Sciences 72, 9 (2015), pp. 1398--1405.

[Fréon and Dagorn 2000] Fréon, Pierre and Dagorn, Laurent, "No Title", Reviews in Fish Biology and Fisheries 10, 2 (2000), pp. 183--207.

[Gilman 2011] Gilman, Eric L., "Bycatch governance and best practice mitigation technology in global tuna fisheries", Marine Policy 35, 5 (2011), pp. 590--609.

[Girard et al. 2007] Girard, Charlotte and Dagorn, Laurent and Taquet, Marc and Aumeeruddy, Riaz and Peignon, Christophe and Benhamou, Simon, "Homing abilities of dolphinfish ( Coryphaena hippurus ) displaced from fish aggregating devices (FADs) determined using ultras...", Aquatic Living Resources 20, 4 (2007), pp. 313--321.

[Gooding and Magnuson 1967] Gooding, Reginald M. and Magnuson, John J., "Ecological Significance of a Drifting Object to Pelagic Fishes", Pacific Science 21 (1967), pp. 486-497.

[Hall 1992] Hall, Martin A., "The association of tunas with floating objects and dolphins in the Eastern Pacific Ocean", in Part VI. Association of fauna with floating objects. Background document for the International Workshop on the Ecology and Fish... (, 1992), pp. 7.

[Hall 1996] Hall, Martin A., "On bycatches", Reviews in Fish Biology and Fisheries 6, 3 (1996), pp. 319--352.

[Hall et al. 2000] Hall, Martin A. and Alverson, Dayton L. and Metuzals, Kaija I., "By-catch: Problems and solutions", Marine Pollution Bulletin 41, 1-6 (2000), pp. 204--219.

[Hallier and Gaertner 2008a] Hallier, J and Gaertner, D, "Drifting fish aggregation devices could act as an ecological trap for tropical tuna species.", Marine Ecology Progress Series 353 (2008), pp. 255--264. 
[Hallier and Gaertner 2008b] Hallier, J and Gaertner, D, "Drifting fish aggregation devices could act as an ecological trap for tropical tuna species", Marine Ecology Progress Series 353 (2008), pp. 255--264.

[Holland et al. 1990] Holland, K. N. and Brill, R. W. and Chang, R. K C, "Horizontal and vertical movements of yellowfin and bigeye tuna associated with fish aggregating devices", Fishery Bulletin 88, 3 (1990), pp. 493--507.

[Hunter and Mitchell 1967] Hunter, J. R. and Mitchell, C. T., "Association of fishes with flotsam in the offshore waters of Central America", Fishery Bulletin 66 (1967), pp. 13-29.

[Ibrahim et al. 1990] Ibrahim, S. and Kawamura, G. and Ambak, MA, "Effective range of traditional Malaysian FAD as determined by fish-releasing method", Fisheries research 9 (1990), pp. 299--306.

[ISSF 2019] Status of the world fisheries for tuna. Oct. 2019. ISSF Technical Report 201912. International Seafood Sustainability Foundation, Washington, D.C., USA.

[Kerr et al. 2009] Kerr, Lisa A. and Secor, David H. and Piccoli, Philip M., "Partial Migration of Fishes as Exemplified by the Estuarine-Dependent White Perch", Fisheries 34, 3 (2009), pp. 114--123.

[Kingsford 1993] Kingsford, MJ J, "Biotic and abiotic structure in the pelagic environment: importance to small fishes", Bulletin of Marine Science 53, 2 (1993), pp. 393--415.

[Klima and Wickham 1971] Klima, Edward F and Wickham, Donald A, "Attraction of Coastal Pelagic Fishes with Artificial Structures", Transactions of the American Fisheries Society 100, 1 (1971), pp. 86--99.

[Koeck et al. 2014] Koeck, Barbara and Pastor, Jérémy and Saragoni, Gilles and Dalias, Nicolas and Payrot, Jérôme and Lenfa..., "Diel and seasonal movement pattern of the dusky grouper Epinephelus marginatus inside a marine reserve.", Marine environmental research 94 (2014), pp. 38--47.

[Kojima 1956] Kojima, Shumpei, "Fishing for Dolphins in the western part of the Japan Sea II- Why do fish take shelter under floaitng materials?", Bulletin of the Japanese Society for Scientific Fisheries 21, 10 (1956), pp. 1049--1052.

[Kojima 1960] Kojima, Shumpei, "Fishing for dolphins in the western part of Japan Sea VI - Behaviours of fish gathering around bamboo rafts", Bulletin of the Japanese Society of Scientific Fisheries 26, 4 (1960), pp. 383--388.

[Lezama-Ochoa et al. 2015] Lezama-Ochoa, N. and Murua, H. and Chust, G. and Ruiz, J. and Chavance, P. and de Molina, A. Delgado and Caballero, A. and Sanc..., "Biodiversity 
in the by-catch communities of the pelagic ecosystem in the Western Indian Ocean", Biodiversity and Conservation 24, 11 (2015), pp. 2647--2671.

[Lopez et al. 2014] Lopez, Jon and Moreno, Gala and Sancristobal, Igor and Murua, Jefferson, "Evolution and current state of the technology of echo-sounder buoys used by Spanish tropical tuna purse seiners in the Atlanti...", Fisheries Research 155 (2014), pp. 127--137.

[Lédée et al. 2015] Lédée, Elodie Ji and Heupel, Michelle R and Tobin, Andrew J and Simpfendorfer, Colin A, "Movements and space use of giant trevally in coral reef habitats and the importance of environmental drivers", Animal Biotelemetry 3, 1 (2015).

[March et al. 2010] March, D. and Palmer, M. and Alós, J. and Grau, a. and Cardona, F., "Short-term residence, home range size and diel patterns of the painted comber Serranus scriba in a temperate marine reserve", Marine Ecology Progress Series 400 (2010), pp. 195--206.

[Marsac and Cayré 1998] Marsac, Francis and Cayré, Patrice, "Telemetry applied to behaviour analysis of yellowfin tuna (Thunnus albacares, Bonnaterre, 1788) movements in a network of fish...", Hydrobiologia 371-372, 0 (1998), pp. 155--171.

[Marsac et al. 2000] Marsac, F. and Fonteneau, A. and Ménard, F., "Drifting FADs used in tuna fisheries: an ecological trap?", Proceedings of the 1st Symposium on Tuna fisheries and FADs, Martinique, October 1999 (2000), pp. 537--552.

[Mason and Lowe 2010] Mason, Tom J. and Lowe, Christopher G., "Home range, habitat use, and site fidelity of barred sand bass within a southern California marine protected area", Fisheries Research 106, 1 (2010), pp. 93--101.

[Matsumoto et al. 2014] Matsumoto, Takayuki and Satoh, Keisuke and Toyonaga, Mikio, "Behavior of skipjack tuna (Katsuwonus pelamis) associated with a drifting FAD monitored with ultrasonic transmitters in the eq...", Fisheries Research 157 (2014), pp. 78--85.

[Menard 2000] Menard, F, "Exploitation of small tunas by a purse-seine fishery with fish aggregating devices and their feeding ecology in an eastern tro...", ICES Journal of Marine Science 57, 3 (2000), pp. 525--530.

[Moreno et al. 2007] Moreno, Gala and Josse, Erwan and Brehmer, Patrice and Nøttestad, Leif, "Echotrace classification and spatial distribution of pelagic fish aggregations around drifting fish aggregating devices (DFAD)", Aquatic Living Resources 20, 4 (2007), pp. 343--356.

[O'Toole et al. 2011] O'Toole, Amanda C. and Danylchuk, Andy J. and Goldberg, Tony L. and Suski, Cory D. and Philipp, David P. and Brooks, Edd and Co..., "Spatial ecology and 
residency patterns of adult great barracuda (Sphyraena barracuda) in coastal waters of The Bahamas", Marine Biology 158 (2011), pp. 2227--2237.

[Ohta and Kakuma 2005] Ohta, I. and Kakuma, S., "Periodic behavior and residence time of yellowfin and bigeye tuna associated with fish aggregating devices around Okinawa Isla...", Marine Biology 146, 3 (2005), pp. 581--594.

[Parin and Fedoryako 1992] Parin, N V and Fedoryako, B I, "Pelagic fish communities around floating objects in the open ocean", in Proceedings of the international Workshop on the Ecology and Fisheries for Tunas Associated with Floating Objects (, 1992), pp. 447--458.

755

[Percival and Walden 2000] Percival, Donald B and Walden, Andrew T, Wavelet Methods for Time Series Analysis (, 2000).

758

759

[RCoreTeam 2014] RCoreTeam, "A Language and Environment for Statistical Computing. R Foundation for Statistical Computing, Vienna, Austria" (2014).

[Raimondi and Keough 1990] Raimondi, Peter T and Keough, Michael J, "Behavioural

[Robert et al. 2012] Robert, Marianne and Dagorn, Laurent and Deneubourg, Jean Louis and Itano, David and Holland, Kim, "Size-dependent behavior of tuna in an array of fish aggregating devices (FADs)", Marine Biology 159 (2012), pp. 907--914.

[Robert et al. 2014] Robert, Marianne and Dagorn, Laurent and Bodin, Nathalie and Pernet, Fabrice and Arsenault-Pernet, Eve-Julie and Deneubourg, Je..., "Comparison of condition factors of skipjack tuna (Katsuwonus pelamis) associated or not with floating objects in an area known...", Canadian Journal of Fisheries and Aquatic Sciences 71, 3 (2014), pp. 472--478.

[Romanov 2002] Romanov, Evgeny V, "Bycatch in the tuna purse-seine fisheries of the western Indian Ocean", Fishery Bulletin 100, 1 (2002), pp. 90--105.

[Rountree 1989] Rountree, Rodney A, "Association of fishes with aggregation devices: effects of strucure size on fish abundance", Bulletin of Marine Science 44, 2 (1989), pp. 960--972.

[Schaefer and Fuller 2005] Schaefer, K. M. and Fuller, D. W., "Behavior of bigeye (Thunnus obesus) and skipjack (Katsuwonus pelamis) tunas within aggregations associated with floating objec...", Marine Biology 146, 4 (2005), pp. 781--792.

[Schaefer and Fuller 2013] Schaefer, Kurt M. and Fuller, Daniel W., "Simultaneous behavior of skipjack (Katsuwonus pelamis), bigeye (Thunnus obsesus), and yellowfin ( $T$. albacares) tunas, within I...", Marine Biology 160, 11 (2013), pp. 3005--3014. 
[Soria et al. 2009] Soria, Marc and Dagorn, Laurent and Potin, Gaël and Fréon, Pierre and Fre, Pierre and Soria, Marc and Dagorn, Laure..., "First field-based experiment supporting the meeting point hypothesis for schooling in pelagic fish", Animal Behaviour 78, 6 (2009), pp. 1441--1446.

[Stehfest et al. 2013] Stehfest, Kilian M. and Patterson, Toby A. and Dagorn, Laurent and Holland, Kim N. and Itano, David and Semmens, Jayson M., "Network analysis of acoustic tracking data reveals the structure and stability of fish aggregations in the ocean", Animal Behaviour 85, 4 (2013), pp. 839--848.

[Taquet 2004] Taquet, Marc, Le comportement agrégatif de la dorade coryphène ( Coryphaena hippurus ) autour des objets flottants (Universite Paris 6, 2004).

[Taquet et al. 2007a] Taquet, Marc and Dagorn, Laurent and Gaertner, Jean-Claude and dolphinfish (Coryphaena hippurus) around drifting FADs as observed from automated acoustic receivers", Aquatic Living Resources 20, 3 (2007), pp. 263--270.

[Taquet et al. 2007b] Taquet, Marc and Sancho, Gorka and Dagorn, Laurent and Gaertner, Jean-Claude and Itano, David and Aumeeruddy, Riaz and Wendling..., "Characterizing fish communities associated with drifting fish aggregating devices (FADs) in the Western Indian Ocean using und...", Aquatic Living Resources 20, 4 (2007), pp. 331--341. determined by tracking with Ultrasonic Devices", Journal of Fisheries Research Board of Canada 27, 2 (1970), pp. 2071--2079. 


\section{Highlights:}

The associative behaviour of oceanic triggerfish (Canthidermis maculata) and rainbow runner (Elagatis bipinnulata) were investigated using acoustic telemetry satellite linked receivers at floating objects in the western Indian Ocean.

Both species remained associated with the same floating object for extended periods with mean residency estimated at 94 days for rainbow runner and 65 days for oceanic triggerfish.

A strong diel pattern was observed for both species with short excursions $(<2 \mathrm{hrs})$ away from the floating objects observed during the day.

Ambient light intensity appears to be the stimulus triggering the onset and end of the associative modes

The observed prolonged residency of these two major bycatch species suggests that they are more vulnerable to the tropical tuna purse seine gear than the targeted tuna species 


\section{Conflict of interest}

The authors declare that they have no conflicts of interest. 